\title{
Postpartum Psikoz Belirtilerinin Kültürel Boyutu ile Ele Alınması: Albasması İnancı ${ }^{1}$ Nazım ŞEN
}

\author{
Arş. Gör., KTO Karatay Üniversitesi, Sosyal ve Beşeri Bilimler Fakültesi, \\ nazim.sen@karatay.edu.tr
}

\begin{abstract}
ÖZET
Bu çalışmada kültürel değerlerin çok kültürlü bir topluma sahip ülkemizde ne anlama geldiği, ifade stili, bölgesel anlam farklılıkları gibi konular çerçevesinde doğum kültürü ele alınmıştır. Doğum kültürü bağlamında en çok inanılan ve ülkemizde en yaygın görülen kavram albasması inancıdır. Albasması inancı ile postpartum psikoz arası ilişki incelenmiş ve benzer noktaların saptanması amaçlanmıştır. Kültürün doğum ile ilişsisinde albasması inancı hemen hemen her kesimin bildiği ve dikkat ettiği bir kavramdır. Yapılan araştırmalara göre albasması belirtileri ile postpartum psikoz tanı kriterlerinin benzerlik gösterdiği sonucuna varılmıştır. Bu iki konunun karşılaştırılmasına yönelik nitel ya da nicel bir çalışma verisine rastlanmamıştır. Bu sonuca bakarak literatüre katkı sağlayacak önemli çalışmaların ortaya çıkacağı düşünülmektedir.
\end{abstract}

Anahtar Kelimeler: Kültür, Albasması, Postpartum, Psikoz, Depresyon

\begin{abstract}
In this study, in our country, which has a multicultural society, birth culture is discussed within the scope of topics such as expression style and regional meaning differences. The most widely believed belief in birth culture and the most common belief in our country is the belief in altar. The relationship between puerperium fever belief and postpartum psychosis has been studied and similarities have been aimed to be determined. Puerperant fever is a belief that almost everybody knows and cares. According to the researches, it has been concluded that postpartum psychosis diagnosis criteria are similar. No qualitative or quantitative study data were found for comparing these two issues. Considering this result, it is thought that important studies will contribute to the literature.
\end{abstract}

Keywords: Culture, Puerperium Fever, Postpartum, Psychosis, Depression

\section{GIRISŞ}

Kültür; toplumun yaşam tarzını belirleyen, geçmişten bugüne getirilmiş olan birtakım değerler, inanç ve davranış kalıplarından oluşmaktadır (Çeltikçi, 2009; Lee ve Brann, 2014). İçinde yaşıyor olduğumuz toplum; tarihi geçmişi, bulunduğu bölge açısından zengin bir

\footnotetext{
${ }^{1}$ Bu makale yüksek lisans eğitimi Kültürel Psikoloji dersi kapsamında oluşturulmuş ve sonrasında geliştirilmiştir. 2020 Uluslararası Van Sosyal ve Beşeri Bilimler Kongresi'nde 24-25 Temmuz 2020 tarihleri arasında sözel bildiri olarak sunulmuştur.
}

Year 4/ 2020, Volume-4, Issue-4 
coğrafi mirasa sahip olması, farklı milletlerden oluşan çok kültürlü bir yapıya sahip olması ve bu çok kültürlülük neticesinde ise ortaya çıkan değerlerin karma bir gelenek kültürünü barındırıyor olmasından ötürü oldukça büyük önem taşır (Bakır ve ark., 2011). Bu değerler her toplumda farklılık göstermekle beraber aynı toplumlar içerisinde de farklı bir anlam taşıdığı görülmektedir (Çeltikçi, 2009). Kültürel kavramları belli bir kalıpta ele almak doğru bir yaklaşım değildir. Kültürün aktarımı doğumla birlikte başlar ve kişiler arası aktarımlar eşliğinde devam eden bir süreçtir (Bozkuş Eğri ve Konak, 2011). Kültürel değerlerimiz hem maddi hem de manevi bir nitelik taşımakla birlikte manevi kültürün etkisi yaşadığımız toplumda oldukça sık görülmektedir (Çeltikçi, 2009). Bir toplumdaki kültürel ögelerin aktarımı ve günümüzde halen uygulanabilir bir nitelik taşıyor olması; toplumun geleneklerine bağlılı̆̆ı ile açıklanabilir (Özdemir, 2009). Ülkemizde yaşatılan birçok gelenek yazılı olarak değil, dilden dile aktarım sonucunda yaşatılan bir miras olduğu görülmektedir. Bu bağlamda ise gelişen her bir kültürel kavramın yerel topluluklara göre farklılaştığı görülmektedir (Yalçın ve Koçak, 2013).

Toplumun belli bir paydasında ortaya çıkan kültürel ögelerin bazı bölgelerde anlamsal olarak farkl1lıklara sahip olduğu görülmektedir (Güleroğlu ve ark., 2014). Kültürel etkileşimlerin etkilediği hususlardan bir tanesi de sağlik faktörüdür (Eğri ve Konak, 2011; Broomfield, 2014). Bireylerin içinde bulundukları kültüre yönelik semboller geliştirdikleri ve topluluk tarafından kabul görülen birtakım tedavi stilleri üzerinde çalışmalar yaparak geleneksel tıp yöntemleri geliştirdikleri görülmektedir (Güleroğlu ve ark., 2014). Geleneksel tıbbın yerini alan birtakım uygulamalar bireylerin tedavilerinde kimi zaman yararlı etkileri olmakla birlikte zarar verdiği durumlarda görülebilmektedir. Bunun yanı sıra herhangi bir etkisinin olmadığ1 fakat yine de inanış açısından olumlu etkisinin olduğuna yönelik kişilerin şemaları bilinmektedir. Toplumun geleneklerine yönelik sağlık uygulamalarına bakıldığında ise ebeveynlik stilleri, anne-çocuk bağlanma stilleri, cinsiyete dayalı şemalar, cinsellik üzerine geliştirilen düşünce kalıpları, evlilik tipleri (çekirdek/geniş aile), doğum öncesi ve sonrasına yönelik inançlar/mitler üzerinde oldukça yoğun uygulamalar yapıldığg görülmektedir (Eğri ve Konak, 2011).

\section{YÖNTEM}

Konu ile ilgili literatüre ulaşabilmek için Google Scholar, DergiPark ve ReserchGate veri tabanları kullanılarak tarama yapılmıştır. Verilere ulaşma noktasında "postpartum psikoz" ve "albasması" anahtar kelimeleri kullanılarak literatüre ulaşılmıştır. Elde edilen literatür ile verileri tanımlamak, detaylandırmak ve ilgili kavramların (postpartum psikoz/albasması) aralarındaki ilişkiyi saptayabilmek adına doküman analizi kullanılarak çalışmanın ilerletilmesi sağlanmıştır. 


\section{DOĞUM KÜLTÜRÜ}

Doğumun yalnızca fizyolojik açıdan bebeğin annesinden ayrılması şeklinde düşünülmesi doğru değildir. Bu süreç hem kadın açısından hem de etrafindaki bireyler açısından oldukça etkileşim gerektiren biyo-psikososyal bir durumdur. Özellikle doğum öncesinde kadının almış olduğu desteğin doğum sırasında ve sonrasında büyük katkısı vardır. Doğumun gerçekleşmesi ile doğum sonrası süreç başlamaktadır. Bu durum yalnızca kadın açısından düşünülmemelidir; doğum ile birlikte sürece katkı sağlayan tüm bireyler de etkilenmektedir (Eğri ve Konak, 2011). Aileye yeni bir üyenin katılımı ile yaşantılarda değişiklikler görülebilmektedir (Ĕgri ve Konak, 2011; Çelik, Çapık ve Engin, 2012; Çarıkci, 2012). Doğum sürecinin kadın için oldukça sancılı bir durum olmasının yanı sıra aile içerisinde hem eş ile ilişkilerde hem de doğum ile ortaya çıan yeni rollerin benimsenip kabul edilmesi açısından oldukça zorlayıcı olabilmektedir. Sosyal düzen içerisinde görülen bu değişimi kabullenmek kolay gibi görünse bile adaptasyon süreci sancılı ilerleyebilmektedir (Serhan, 2010).

Gebelik kültürü; inanç stilleri, gelenekler, ebeveynlik stilleri gibi her toplumda farklı değer taşımaktadır. Buna rağmen gebeliği biyo-psikososyal açıdan ele almak oldukça önemlidir. Gebelik ve doğum süreci biyolojik bir durum olmanın yanı sıra kişinin psikolojik durumunu, sosyal çevre ile iletişimini oldukça etkileyen bir süreçtir (Bakır ve ark., 2011). Doğum ile birlikte kültürün de kişilik gelişimi üzerinde etkisi vardır; Hayes, Roberts ve Davare'e (2000) göre ebeveynlik rollerinin değişimi, çocuğa bakım verme stilleri, dil gelişimi gibi pek çok faktör bebeğin gelişimde önemli rol oynar (Kahriman, 2007).

Yapılan araştırmalara göre bireylerin çocuk sahibi olma istekleri kültürler arası ortak bir değer taşımaktadır. Soyun devamı, çocuğun cinsiyeti, ebeveynlik stilleri, geniş aile faktörleri gibi birçok durum neticesinde toplumlar arasında birtakım şemalar ortaya çıkmıştır. Kültürel değerlere bağlı olarak oluşan inanç sistemlerinde yapılan uygulamalar genel anlamda kadınlar üzerinden yürütülmektedir. Toplumsal değerlerimize baktığımızda ise çocuk genellikle bir bağlayıcılık ifade etmektedir. Aile olmanın ilk aşaması olarak nitelendirilmiş ve çocuk sahibi olamayan ya da olmak istemeyen aileler hakkında kusurluluk şemaları (değersizlik hissi, utanç, basitlik vb.) oluşturulmuştur. Bu hususta ise uygulamalar genellikle kadın üzerinden yürütülmüş olup kadına yönelik değersizlik duygusu atfedilmiş ve buna bağlı olarak da eşlerin birbirleri ile iliş̧kilerinde sorunlar ortaya çıkmaktadır. Eşlerin ikili ilişkilerde yaşadıkları problemlerin yanı sıra özellikle kadında değersizlik hissi, beden algısına yönelik negatif tutumlar, sosyal ilişkilerden kaçınma gibi durumların meydana gelmesi söz konusudur (Yalçın ve Koçak, 2013).

Geleneklere bağlı olarak yapılan uygulamalar kimi zaman anne ve çocuk üzerinde olumsuz etkiler bırakmaktadır. Doğum kültüründe sürdürülen gelenekler doğum öncesinden başlayıp doğum sırasında ve doğum sonrasında da devam etmektedir. Fakat bu süreçler ele alınırken dikkat edilmesi gereken annenin ve bebeğin sağlığı olmalıdır (Özmen, Çetinkaya ve Cambaz, 2008). Bazı kültürel uygulamalara baktığımızda anne-çocuk sağlığını ciddi anlamda tehlikeye

Year 4/ 2020, Volume-4, Issue-4 | WwW.ispecjournal.org 
sokacak hatta ölümlere bile sebep olabilecek durumlar içerebilmektedir. Bu durumun önüne geçebilmek için toplumu bilinçlendirmek oldukça önem arz etmektedir (Leninger, 2002).

Geleneksel tıp yöntemleri doğum öncesi, doğum sırası ve doğum sonrasında uygulanabilmektedir (Çelik, Çapık ve Engin, 2012; Canbay ve Çitil, t.y.). Ancak genellikle postpartum dönemde oldukça sık karşımıza çıkmaktadır (Bozkuş Eğri ve Konak, 2011). Bu tür uygulamaların ortaya çıkmasındaki asıl sebepler bölgesel sağlık hizmetlerindeki yetersizlikler, maddi kısıtlılıklar ve doğum sonrası gerçekleştirilen inanç ritüelleri (gizlilik, utanç vb.) olabilmektedir (Gigger, Davidhizar ve Wieczorek, 1993). Ancak bu uygulamaların yararlı olanlarının yanı sıra hiçbir etkisi olmayan ya da zarar verici yönleri de vardır (Çelik, Çapık ve Engin, 2012). Kültürel inançlar ve birtakım yetersiz koşullar çerçevesinde birçok kadının doğum süreçleri ve sonraki aşamalarında problemler meydana gelebilmektedir (Biltekin ve ark., 2004). Geleneksel tıp yöntemleri üzerinde yapılan çalışmalar incelendiğinde ise bakım verme/emzirme/lohusalık dönemleri üzerine çalışmaların yoğunlukta olduğu görülmektedir (Çelik, Çapık ve Engin, 2012).

Kültürün de etkisiyle normal doğumun, kadını anne yapacağına, manevi boyutta bir arınma yaşayacağına yönelik inançlar görülmektedir (Aktaş ve Erkek, 2018). Vajinal doğum ile inanılan bir diğer inanış ise "anneliğin normal doğum ile kazanılan bir durum" olduğuna yönelik şemalardır. Bu şemaların gelişimi ise yine kültürün etkisiyle mümkün olmaktadır (Duran ve Atan, 2011). Bunun yanı sıra sosyal çevreden duyulan doğuma yönelik olumlu tutumlar, doğum sonrası hızlı toparlanma, acının doğuma yönelik verdiği haz gibi ifadelerin kadınların vajinal doğumu tercih etmelerinde önemli bir etkiye sahip oldukları görülmektedir. Ek olarak doğum korkusu, doğumda yaşanan komplikasyonlar, sağlik personelinin destek yetersizliği gibi olumsuz otomatik düşünceler/şemalar, sağlık çalışanlarının negatif tutumları gibi sebepler sonucunda anne adaylarının sezaryen doğumu tercih ettikleri de görülmektedir. Doğum tercihinin tek başına kültür bağlamında ele alınması doğru değildir. Biyolojik anlamda da sağlıklı bir vajinal doğum ile anne-bebek etkileşimi daha hızlı gelişebilmekte ve iyileşme süreci daha hızlı olmaktadır (Aktaş ve Erkek, 2018). Bu da anne-bebek iletişimini arttıran, bağlanma kuramı çerçevesinde ele alınan bir diğer önemli konudur. Anne ve bebek arası etkileşim ilk olarak anne karnında başlar ve doğum sonrası süreçte de devam eder. Sağlıklı bir bağlanmanın gerçekleşebilmesi için annenin sosyal destek alması, bebek bakımı konusunda hem kadının hem de bebeğe bakım veren bireylerin bilinçlendirilmesi sağlıklı bir gelişim için oldukça önemlidir.

Sağlık hizmetlerinin yetersiz olması durumunda ya da sağlık çalışanlarının bulunduğu bölgede önemli olan içinde bulunulan kültürün örf ve adetlerini öğrenmektir. Toplumun kültürüne uyum sağlayarak bireylere yaklaşmak ve tıbbi bilgilendirmenin bu doğrultuda yapılması, kişilerin hem bilinçlenmesi doğrultusunda hem de kültüre bağlı yanlış uygulamaları anlamlandırmaları konusunda oldukça büyük önem taşımaktadır (Erbil ve Sağlam, 2010). 


\subsection{Albasması İnancı}

Kültürel değerler içerisinde geliştirilmiş olan inanışlar toplumlar arası farklılıklar göstermektedir. Buna rağmen bazı kavramlar içinde bulunulan çok kültürlü toplumda aynı ifade tarzlarına sahip olabilmektedir (Güleroğlu ve ark., 2014).

Özellikle doğumun kültürel anlamda etkileri incelendiğinde toplumumuzda en çok bilinen ve inanılan değer albasması inancı olarak karşımıza çıkmaktadır. Albasması inancı kültürel olarak çok eskilere dayanmaktadır. Bakır, İnci, Alan, Gökyıldız ve Elmas'a (2011) göre kültürel olarak albastı, al karısı, almis, goncalas, cangoloz, Irmak'a (2016) göre körmös gibi birçok isimle anılabilmektedir. Albasmasının kötü bir ruh olduğu inancı ile "uzun boylu, uzun parmak ve tırnaklı, dağınık saçlı, yağlı vücutlu, el ve ayakları küçük, dişlek, bir dudağı yerde bir dudağı gökte, bazen zenci suratll, memelerini masallardaki devler gibi omuzlarından geriye atabilen, tepesinde gözü olan, çok çirkin, al gömlek giyen bir yaratık” olarak tanımlanmaktadır (Hotun, 1990).

Doğum sonrası süreçte albasması tanımına yönelik olarak kültür bağlamında birtakım inanışlar ortaya çıkmıştır; doğum yapan kadının yalnız bırakılmaması, karanlıkta kalmaması gibi inançlar geliştirilmiştir. Albasması aynı zamanda al karısı olarak da bilinmektedir. Bunun nedeni kötü ruhun kadın kıyafetleri giyerek doğum sonrasında kadını korkutmak istediği ve nefessiz bıraktığı inancıdır (Bolçay, 2011). Albasmasına yönelik toplumda geliştirilen birtakım kültürel uygulamalara baktığımızda:

- İlk lokmanın doğum yapan kadından önce başka bir birey tarafindan yedirilmesi

- Lohusanın kabrinin kırk gün açık olduğu

- Kur'an-1 Kerim ile ekmek koyarak korunma yöntemleri

- Albasmasının erkek kıyafetlerinden korkması ve bu yüzden odada erkek kıyafeti bulundurma

- Soğan ve sarımsak gibi kokulu besinlere albasmasının gelmemesi

- Kesici aletler (makas, biçak vb.) bulundurarak kötü ruhun uzak tutulması

Tüm bu uygulamalara ek olarak ise lohusanın başına doğum sonrası kırmızı kurdelenin bağlanmasındaki esas etken albasmasından korunmaktır. Albasmasının kırmızı renkten korktuğu ve bu yüzden kadına yaklaşamadığına inanılmaktadır. Bunun yanı sıra Beyaz’a (2014) göre postpartum dönemde kadın ilk 3 ila 7 gün hiçbir şekilde yalnız bırakılmaz. Işıklar geceleri kapatılmaz; bunun nedeni ise albasmasının gecenin olmadığına inandırılmak istenmesidir. Albasması inancına dikkat edilmemesi halinde gece olduğunda loğusa kadına albasması gelir; nefesini keser. Bu esnada kadın sesini duyuramaz, çı̆̆lık atamaz, uyanamaz Year 4/ 2020, Volume-4, Issue-4 | WWW.ispecjournal.org 
(Yüksel, 2007). Albasması inancı postpartum dönemde özellikle ilk 40 gün içerisinde ortaya çıkmakta ve bu kötü ruhun amacının anne ile bebeğe zarar verme olduğu bilinmektedir. Postpartum dönemde annenin gücünü hemen toparlayamaması ve bu durumdan faydalandığına inanılan albasmasının uzaklaştırılması inancı yer almaktadır. Bu dönemde anne ve bebeğin özellikle yalnız bırakılmaması gerektiğine inanılır (Çarıkçi, 2012; Bakır ve ark., 2011).

Albasması literatürü incelendiğinde ise psikopatoloji bağlamında postpartum psikoz ile benzerlik gösterdiği dikkat çekmektedir. Postpartum psikoz DSM tanı kriterlerinde başlı başına bir rahatsızlık olmamakla birlikte depresif bozukluklar başlığı altında yer almaktadır. Buna bağlı olarak da postpartum depresyon ve psikozu bir arada düşünmek ve bu patolojileri değerlendirmede dikkat etmek gerekmektedir.

\section{POSTPARTUM PSİKOZ}

Postpartum psikoz tarihte ilk olarak 19. yy.'da Esquirol aracıllğı ile tanımlanmış olup bireylerin başlı başına postpartum psikoz belirtileri taşımadığını; manik, depresif belirtilerin eşlik etmesi durumu ile ortaya çıktığı görülmüştür (Demirkol, Kızıltoprak ve Şenbayram, 2018). Komorbit görülebilen bir hastalık olduğu için tespit edilmesi oldukça zordur (Rohde ve Marneros, 1993). Epidemiyolojisi incelendiğinde ise 1000 doğumda 1-2 vaka olarak karşımıza çıkmaktadır (Rohde ve Marneros, 1993; Sharma ve Mazmanian, 2003; Sit, Rothschild ve Wisner, 2006; Spinelli, 2009). Doğum sonrası her 1000 kadından 2'si intihar girişiminde bulunmuştur (Sit, Rothschild ve Wisner, 2006). Doğumdan sonraki ilk 2-3 gün içerisinde hastada paranoid, grandiyöz, tuhaf sanrılar, duygudurumda sıçramalar, kafa karışılığı, davranış bozuklukları gibi hafif ve geçici semptomlar büyük ölçüde ortaya çıkabilmektedir (Sharma ve Mazmanian, 2003; Sit, Rothschild ve Wisner, 2006). Postpartum psikoz semptomlarının 10-14 gün içerisinde görüldüğü bilinse de postpartum dönemin ilk 30 günü içerisinde ortaya çıkması söz konusudur (Rohde ve Marneros, 1993; Sharma ve Mazmanian, 2003; Sit, Rothschild ve Wisner, 2006; Spinelli, 2009). Doğum sonrası ilk ay içerisinde psikoz belirtilerinin ya da manik döngünün görülmesi durumu, normal zamana göre 23 kat daha yüksektir (Demirkol, Kızıltoprak ve Şenbayram, 2018). İlk doğum ve ilk haftada oranlar oldukça yüksek seyredebilirken hastalığın ortaya çıkışı 5 . haftayı bulabilmektedir (Rohde ve Marneros, 1993). Postpartum dönemde psikoz belirtileri hastalık seyrinin 3 aya kadar uzadığı bilinmektedir (Demirkol, Kızıltoprak ve Şenbayram, 2018). Buna ek olarak yapılan çalışmalarda 8 . doğuma kadar da psikoz belirtilerinin ortaya çıktığı görülmektedir (Rohde ve Marneros, 1993). Rohde ve Marneros'a (2003) göre huzursuzluk, kayg1, katatonik davranışlar, uyku problemleri, depresif duygudurum, Spinelli'ye (2009) göre hafıza kayıpları, tuhaf (bizarre) davranışlar, geri çekilme, halüsinasyonlar, Sit, Rothschild ve Wisner'a (2006) göre kafa karışıklığı postpartum psikozda görülebilen durumlardır. Psikoza bağlı olarak kişide dezorganize davranışlar (tuhaf, kopuk), depersonalizasyon (bedeninden kopma, düşüncelerden ayrışma), düşüncelerde dağılma görülebilmektedir (Özdemir, 2007). Doğum sonrası dönemde huzursuzluk ve paranoid semptomlar öncelikli olarak karşımıza çıkmaktadır Year 4/ 2020, Volume-4, Issue-4 | www.ispecjournal.org 
(Rohde ve Marneros, 1993). Uyku problemlerinin yaşanması da psikoz belirtilerini tetikleyen unsurlar arasındadır (Sharma ve Mazmanian, 2003).

Postpartum psikoz ile ilgili çalışmalar incelendiğinde \%30-70 arasında farklı psikopatolojiler (sıklıkla bipolar bozukluk) ile birlikte ortaya çıktığı görülmüştür (Sharma ve Mazmanian, 2003). Bu psikopatolojiler bireylerin anamnez bilgileri ve geçmiş psikiyatrik öykülerin durumu son derece önemlidir (Spinelli, 2009; Demirkol, Kızıltoprak ve Şenbayram, 2018). Bir defa geçirilmiş olan psikoz; sonraki dönemlerde de tekrarlayıı bir etki sunabilir (Demirkol, Kızıltoprak ve Şenbayram, 2018). Postpartum psikoz durumu bireyin öyküsünde daha önce de yer almışsa \%25-57 aralığında nüksetme durumu söz konusudur. Evlilik öncesi doğum, yaş kriteri, psikopatolojik yaşantı geçmişi, psikoz öykülerinin yer alması, postpartum psikoz ihtimallerini arttırmaktadır (Akyüz Çim, 2017). Postpartum psikozu, psikotik bozukluklar bağlamında ele aldığımızda Rohde ve Marneros (1993) kadınların \%49'unun şizoaffektif ve \%28'inin şizofreni hastalığına sahip; Amankwaa'ya (2003) göre \%10-15 oranında postpartum depresyon etkisinin görüldüğ̈̈; Sit, Rothschild ve Wisner'a (2006) göre bipolar ya da şizoaffektif vakalarda görülme sıklığının \%72-88 oranında seyrettiği ve doğum sonrası dönemde annelik hüznünün \%50-75 daha yaygın olarak görülebildiği bulgulanmıştır. Postpartum psikozu; annelik hüznü ile postpartum depresyondan ayıran özelliği ise varsanı ve sanrıların görülmesi, hezeyana bağlı olarak annenin bebeğini şeytan gibi algılanması ve bebeğini öldürme isteği taşıması gibi belirtiler ile ortaya çıkmaktadır (Özdemir, 2007).

Postpartum psikoz anne-bebek etkileşimini oldukça etkiler (Rohde ve Marneros, 1993). Postpartum psikozda ortaya çıkan sanrılar çoğunlukla yenidoğan ile ilişkilidir (Akyüz Çim, 2017). Annenin bebeğine karşı zarar verici tutum ve davranışları olabilmektedir (Rohde ve Marneros, 1993). Psikoza girmiş bir kadın, doğum sonrası dönemde bebeğine yönelik bir takım doğru olmayan inanç sistemlerine girebilmektedirler (Kocabaşoğlu, Balcıoğlu ve Şen, 1995); bebeği saklamaya ve korumaya yönelik sanrılar ortaya çıkabilmektedir (Rohde ve Marneros, 1993). Bebeğine yönelik bir aitlik hissetmeme, çevreden kötülük göreceğine yönelik şemaları ya da bebeği korumaya yönelik bir takım zarar verici tutumlar ve bebeğe yönelik özkıyım durumu ortaya çıkabilmektedir (Kocabaşoğlu, Balcıŏlu ve Şen, 1995). Postpartum psikoza (PP) sahip kadınların \%4'ünde de bebeğe zarar verici tutumların görülebildiği ve özkıyım ile sonuçlanmaların yaşandığı görülebilmektedir (Demirkol, Kızıltoprak ve Şenbayram, 2018). PP olan kadınların \%28-35'i bebeğine yönelik sanrıları varken; \%9'unun bebeğine zarar verme düşüncelerine sahip olduğu görülmüştür (Sit, Rothschild ve Wisner, 2006). Rohde ve Marneros'a (1993) göre zarar verme/bebeği öldürme davranışları 50.000 doğumda 1 görülen bir durum olarak karşımıza çıkmaktadır. Annenin bebeğine yetebilme düşüncesi, zarar verme endişesi yaşaması gibi durumlara ek olarak fizyolojik olarak da annenin yorgunluk, uykusuzluk, dikkatte dağılma, ajite olma gibi durumlar yaşaması bebek-anne ilişkisine zarar vermekte ve anneyi bebekten uzaklaştırabilmektedir (Özdemir, 2007). Bebeğin tehlike altına girmesinin önüne geçebilmek için yenidoğan bakımı ve hastanın iyileşmesini sağlamak oldukça önemlidir (Sit, Rothschild ve Wisner, 2006). Postpartum süreçte kadın eğer ki doğum sonrası psikoz belirtileri ile bebeği öldürme/zarar verme düşünceleri yer almıyorsa bebek anneden uzak tutulmamalı hatta 
kontrollü bir şekilde anne ile teması sağlanmalıdır. Bu sayede hem annenin bebeğine yakınlık duyması sağlanmalı hem de bebeğin geliştireceği anne-bebek duygusal bağının oluşumu desteklenmelidir (Özdemir, 2007).

Postpartum psikoz, anne tarafından istenmeyen gebelik, aile içi geçimsizlik/mutsuzluk; doğumda gerçekleşen yoğun kanama, enfeksiyon gibi durumlara bağlı olarak da gelişebilmektedir (Özdemir, 2007). Hayes, Roberts ve Davare'e (2000) göre doğuma ilişkin komplikasyonlar, hamilelikte algılanan stres, düşük gelirli olmak, bebeğin doğumuna yönelik tıbbi faktörlerin de etkisi bu dönemde oldukça etkilidir.

Postpartum dönemde kadınların yaşam kaliteleri ile ilgili değiş̧kenleri incelediğimizde; eğitim düzeyi, çalışma durumu, aylık gelir faktörlerinin etkilerinden söz edilmektedir. Eğitim düzeyi yükseldikçe (Durukan ve ark., 2011; Yıldırım, Hacıhasanoğlu ve Karakurt, 2011; Kolukırık, 2016; Karamustafa, 2017), kadınların çalışma hayatlarının olması durumunda (Kolukırık, 2016) ve yüksek gelir düzeyine sahip ailelerin (Bingöl ve Tel, 2007; Özdemir, 2007; Gülnar, Sunay ve Çaylan, 2010; Yıldırım, Hacıhasanoğlu ve Karakurt, 2011; Durukan ve ark., 2011; Karamustafa, 2017) postpartum dönemde yaşadıkları sorunların daha az oldukları saptanmıştır.

Doğum ile ilgili komplikasyonlar ele alındığında ise bebeğin erken doğumu, istenmeyen gebelik oluşu, çok çocuk sayısının varlığı, bebeğin engelli ya da bir hastalık ile dünyaya gelmesi gibi durumlarda postpartum depresyon ve psikoz görülme sıklığı artmaktadır (Özdemir, 2007; Bingöl ve Tel, 2007; Durukan ve ark., 2011; Karamustafa, 2017; Şahin, 2018). Gebelik öncesi doğumun vajinal ya da sezaryen olacağı ile ilgili olarak anne adayının bilgi sahibi olması ve doğum esnasında planlanmayan bir durumdan kaynaklı doğum şeklinin değişiklik göstermesi de stres ile bağlantılı olarak postpartum depresyon ve psikozun görülme sıklığını arttırıcı bir etken olarak bulunmuştur (Karamustafa, 2017).

Doğum sonrası dönemde annede; bebeğine karşı yeterlilik duygusu ile ilgili birtakım sorunlar ortaya çıkabilmektedir (Bingöl ve Tel, 2007; Karamustafa, 2017). Bundan dolayı doğum sonrası dönemde depresif belirtileri önlemek amaçlı yakın çevre ile arkadaş gruplarının desteği oldukça önemlidir. Yapılan araştırmalar sonucunda kadınların \%60'ının sosyal destek ihtiyacı olduğu bulgulanmıştır (Bingöl ve Tel, 2007). Sosyal desteğin zayıf olması halinde anne yetersizlik algısina kapılarak postpartum depresyonun ya da psikoz sürecinin ortaya çıkışını hızlandırabilmektedir (Bingöl ve Tel, 2007; Karamustafa, 2017). Kadının aile ilişkilerinin iyi olması; evlilik memnuniyeti, eşler arası ilişkinin iyilik hali ve bebek bakım konusunda desteğin varlığ 1 söz konusu olduğu durumlarda postpartum depresyonun ve psikozun görülme sıklığı azalmaktadır (Kolukırık, 2016).

Çok kültürlü toplumlarda aile desteği, bebek bakımı noktasında ebeveynlerin yetersizliği ve bundan kaynaklı aile büyüklerinin bebek bakımı noktasında yardımcı olmaları süreci kolaylaştırıcı bir etkiye sahiptir. Ancak bebek bakımı noktasındaki ilk çatı̧̧ma aile büyükleri ile anne arasında geçebilmektedir. Destekleyici ebeveynlerin varlığı, yenidoğan

Year 4/ 2020, Volume-4, Issue-4 | WwW.ispecjournal.org 
bakımına katkı sağlasa da eskiye göre daha gelenekselci bir tutum ile bebeği yetiştirme noktasında birtakım sorunlar yaşanabilmektedir (Lee ve Brann, 2014).

Sosyal desteğin yetersizliği, eşlerin karar verme/problem çözmedeki tutumları (Lee ve Brann, 2014) ve yakın çevrenin ilgisiz tutumları ya da gebelik boyunca stres altında olmak, geçmiş depresif öykü/psikiyatrik rahatsızlık ya da kronik bir rahatsızlığın varlığı gibi durumlarda postpartum depresyonu tetikleyen faktörler arasındadır (Bingöl ve Tel, 2007; Özdemir, 2007; Durukan ve ark., 2011; Kolukırık, 2016; Karamustafa, 2017; Şahin, 2018).

\section{TARTIŞMA VE SONUÇ}

Doğum kültüründe sıklıkla karşımıza çıkan albasması ile ilgili çalışmaların postpartum psikoz ile bağlantısı açısından yapılmış araştırma bulgularına rastlanmamıştır. Albasması kültürel boyutta ele alınan ve edebiyat, gelenekler, hizmet sektörü açısından katkı sağlayan bir konudur ancak psikoloji bilimi çerçevesinde değerlendirmeler oldukça kısıtlıdır. Postpartum depresyon/psikoz hakkında ülkemizde yapılan çalışmaların kısıtlılığı da literatürdeki yetersizliğini ortaya koymaktadır. Postpartum psikozun kültür bağlamında literatürü taranmış ve Doğu toplumlarına yönelik bulgular elde edilmiştir. Doğu toplumlarında kadınların kültürel anlamda doğum sonrası dönemde depresiflik durumuna daha yatkınlık gösterebilecekleri görülmektedir (Halbreich ve Karkun, 2005). Doğuma yönelik kültürel uygulamalara baktığımızda ise doğum sonrasında kadının evde kalması ya da eve kapatılması durumu söz konusudur. Burada esas amaç annenin bebeği ile bağ kurması ve ilgilenmesi olarak tanımlanır. Annelikte sosyal desteğin önemi, doğum sonrası cinsel faaliyetlerin kısıtlanması, ağız bakımı, dengeli ve düzenli beslenme unsurları da toplumumuz ile benzerlik gösteren durumlardır (Lee ve Brann, 2014). Sosyal desteğin hem duygusal hem fiziksel özelliklerinin olması doğum sonrası dönemde kadın için koruyucu bir özellik sağlamaktadır. Bireylerin özellikle içinde bulundukları toplumda dezavantajlı bir özellik taşıor olmalarından dolayı depresiflik durumlarına karşı iyi ve güçlü annelik durumunun idealleştirilmesi söz konusu olabilmektedir (Broomfield, 2014). Bu bağlamda kadınlarda depresif duygudurumun ortaya çıkmasında temel sebep sağlı hizmetlerindeki yetersizlikler değil; günlük stres faktörleri, önyargılar, toplumdan farklılaşma (Halbreich ve Karkun, 2005) ve dişlanma hissinin varlığıdır (Broomfield, 2014). Tecrübe edilen yaşantıların olumsuz olmasına bağlı olarak depresif tutumun görülmesi ve psikotik özelliklerin ortaya çıkması söz konusu olabilmektedir. Özellikle kültürel bağlamda ele alınan değerler ile psikopatoloji arasındaki ilişkinin incelenmesi ve bu hususta yapılacak çalışmaların literatüre katkı sağlayacağ düşünülmektedir. Ülkemiz veri toplama ve araştırma kapsamında istenilen katılımcı gruplarına ulaşma açısından oldukça çeşitlilik göstermektedir. Araştırma konusu gereği belirli gruplardan veri elde ederek literatüre daha nesnel sonuçların aktarılması çok büyük önem arz etmektedir. Bu doğrultuda ortaya çıkan çalışma konuları değerlendirilmeli ve çalışmaların literatüre katkı sağlayacağı düşünülmektedir. 
Kültürün etkisi ile ortaya çıkan gelenekler çoğu zaman topluluklar arası farklılık göstermekle birlikte bazı değerlerin aynı şekilde kullanıldığını görmekteyiz. Bu değerler içerisinde doğum kültürü bağlamında ele aldığımız albasması kavramının araştırmalar neticesinde topluluklar arasında aynı değeri taşıdığı görülmüştür. Bu çalışmada kültürel değerler olarak bilinen kavramların psikoloji bilimi içerisindeki patoloji bulguları açısından değerlendirmesi yapılmış olup psikopatoloji bağlamında konunun taraması gerçekleştirilmiştir. Yapılan araştırmalar sonucunda ise albasması kavramının kötü bir ruh olarak bilindiği, doğumdan sonraki kırk gün içerisinde özellikle görülebildiği ve anne-bebek ilişkisini olumsuz etkilediği gibi bulgulara rastlanmıştır. Aynı zamanda annenin doğum sonrasında yalnız bırakılmaması, ihtiyaçlarının giderilmesi, düzenli bir beslenme programına dahil edilmesi, erkek bireyin kadına destek olması gibi kültür bağlamında da önem verilen değerler saptanmıştır. Bu süreci psikopatoloji bağlamında en iyi postpartum psikoz bağlamında ele almak doğru olacaktır. Postpartum psikozda görülen varsanıların, albasmasında kötü ruh olarak tanımlanan kavrama karşılık geldiği; albasmasında anne-bebek sağlığının korunması için kırk güne yakın bir süreçte takibin yapılması hususunun postpartum psikozda doğum sonrası 2. haftadan başlayıp ortalama 2-3 ay kadar devam etmesinin söz konusu olması ile benzerlik gösterdiği görülmektedir. Albasmasına yönelik sosyal destek, doğuma ilişkin tutumlar, doğumdan kaynaklanan komplikasyonlar, inanç ve gelenekler doğrultusunda gelişen kültürel değerlerin postpartum psikozda sürecin atlatılması için yordayıcı nitelik taşıyan benzer uygulamaların olduğu saptanmıştır. Bu doğrultuda postpartum psikoz ile kültürel bir değer olan albasması kavramının bilimsel ve kültürel ögeler olarak birbirlerinin tamamlayıcısı oldukları düşünülmektedir.

\section{KAYNAKÇA}

Aktaş, S., \& Erkek, Z. Y. (2018). Annelerin vajinal doğumu tercih etme nedenlerinin incelenmesi: Bir nitel araştırma örneği. Gümüşhane Üniversitesi Sağlı Bilimleri Dergisi, 7(1), 111-124.

Akyüz Çim, E. F. Postpartum psikoz. Van Tıp Dergisi, 24(2), 131-134.

Amankwaa, L. C. (2003). Postpartum depression among African-American women. Issues in mental health nursing, 24(3), 297-316.

Bakır, E., İnci, H., Alan, S., Gökyıldız, Ş., \& Elmas, E. (2011). Adana'da albasması inanışı ve geleneksel uygulamalar. Mersin Üniversitesi Tıp Fakültesi Lokman Hekim Tıp Tarihi ve Folklorik Tip Dergisi, 1(1), 13-18.

Beyaz, D. (2017). Doğum ritüelinin demonik varlığı: gelincik basması. III: Uluslararası Genç Halkbilimciler Sempozyumu, Hacettepe Üniversitesi Yayınları, 39-46. 
Biltekin Ö., Boran ÖD., Denkli MD., Yalçınkaya S. naldöken sağlık ocağı bölgesinde 0-11 aylık bebeği olan annelerin doğum öncesi dönem ve bebek bakımında geleneksel uygulamaları. STED 2004;13(5):166-8.

Bingöl, T. Y., \& Tel, H. (2007). Postpartum dönemdeki kadınlarda algılanan sosyal destek ve depresyon düzeyleri ile etkileyen faktörler. Anadolu Hemşirelik ve Sağlık Bilimleri Dergisi, 10(3), 1-6.

Bolçay, E. (2011). Erzurum'da doğum öncesi, doğum sonrası ve çocukluk dönemiyle alâkalı gelenekler. Kastamonu Eğitim Dergisi, 19(2), 587-600.

Bozkuş Eğri, G., \& Konak, A. (2011). Doğum sonu dönem ile ilgili geleneksel inanç ve uygulamalara dünyadan ve Türkiye'den örnekler. Zeitschrift für die Welt der Türken/Journal of World of Turks, 3(1), 143-155.

Broomfield, R. (2014). African American women and postpartum depression.

Canbay, F. Ç., \& Çitil, E. T. t.y. Doğum sonrası anne ve bebek bakımına ilişkin kültürel yaklaşımların etkisi. Erişim Adresi: https://www.gecekitapligi.com/Webkontrol/uploads/Fck/yayin2_4.pdf\#page=36. (Haziran 1, 2020) Sağlık Bilimleri Alanında, 36.

Çarıkci, Y. (2012). Kadınların gebelik, doğum ve doğum sonu dönem bakımına yönelik geleneksel uygulamaları (Doctoral dissertation, Sağlık Bilimleri Enstitüsü).

Çelik, A. S., Çapık, A., \& Engin, R. (2012). Erzurum'da gebelik ve doğum sonu dönemde yapılan geleneksel uygulamaların belirlenmesi. Anadolu Hemşirelik ve Sağlık Bilimleri Dergisi, 15(4), 262-267.

Çeltikci, O. (2009). Türk dünyası kültüründe doğum üzerine ortak uygulamalar.

Demirkol, M. E., Kızıltoprak, A., \& Şenbayram, Ş. (2018). Postpartum psikoz. Arşiv Kaynak Tarama Dergisi, 27(2), 206-222.

Duran, E. T., \& Atan, Ş. Ü. (2011). Kadınların sezaryen/vajinal doğuma ilişkin bakış açılarının kalitatif analizi. Genel Tip Dergisi, 21(3).

Durukan, E., İlhan, M. N., Bumin, M. A., \& Aycan, S. (2011). 2 hafta-18 aylık bebeği olan annelerde postpartum depresyon sıklı̆̆ı ve yaşam kalitesi. Balkan Medical Journal, 2011(4), 385-393.

Erbil, N., \& Sağlam, G. (2010). Gebelikte bebeğin cinsiyetini belirleme ve tahmin etmeye ilişkin geleneksel inanç, uygulamalar ve bazı sosyo-demografik özelliklerle ilişkisi. Uluslararası İnsan Bilimleri Dergisi, 7(1), 347-359.

Gigger, J. N., Davidhizar, R. E., \& Wieczorek, S. C. (1993). Culture and etnicity. maternity and gynecologic care: the nurse and the family. (5th Ed.). Mosby-Year Book, Inc, 42-67. 
Güleroğlu, F. T., Başer, M., Cerit, E., \& Yüzer, S. (2014). Postpartum dönemde yapılan geleneksel inanç ve uygulamalar. Journal of Clinical Obstetrics \& Gynecology, 24(2), 84-89.

Gülnar, D., Sunay, D., \& Çaylan, A. (2010). Postpartum depresyon ile ilişkili risk faktörleri. Journal of Clinical Obstetrics \& Gynecology, 20(3), 141-148.

Halbreich, U., \& Karkun, S. (2006). Cross-cultural and social diversity of prevalence of postpartum depression and depressive symptoms. Journal of affective disorders, 91(2-3), 97111.

Hayes, M. J., Roberts, S., \& Davare, A. (2000). Transactional conflict between psychobiology and culture in the etiology of postpartum depression. Medical hypotheses, 54(1), 7-17.

Hotun, N. (1990). İstanbul ili Halkalı bölgesindeki kadınların gebelik ve doğuma ilişkin geleneksel inanç ve uygulamaları. Yayınlanmamış Yüksek Lisans Tezi, İstanbul, İstanbul Üniversitesi, Sağlık Bilimleri Enstitüsü.

Irmak, Y. (2016). Doğumdan ölüme Bingöl geçiş dönemleri inanç ve uygulamaları. Bingöl Üniversitesi Sosyal Bilimler Enstitüsü Dergisi (BUSBED), 6(11), 113-132.

Kahriman, İ. (2007). Trabzon il merkezinde 6-12 aylık çocuğu olan annelerin bebek bakımına ilişkin geleneksel uygulamaları (Yüksek Lisans Tezi). Trabzon: Karadeniz Teknik Üniversitesi.

Karamustafa, F. C. (2017). Postpartum depresyonda evlilik doyumu ve benlik saygisının incelenmesi (Master's thesis, Işı1k Üniversitesi).

Kocabaşoğlu, N., Balcığlu, Đ., \& Şen, C. (1995). Puerperal (doğum sonrasi) psikoz. Perinataloji Dergisi, 3(1-2), 67-69.

Kolukırık, Ü. (2016). Postpartum depresyon belirtisini etkileyen etmenler ve postpartum depresyon belirtisinin emzirme ile ilişkisi. Yayınlanmamış uzmanlık tezi. Dokuz Eylül Üniversitesi Tıp Fakültesi Halk Sağlı̆̆ Anabilim Dalı.

Lee, A., \& Brann, L. (2015). Influence of cultural beliefs on infant feeding, postpartum and childcare practices among Chinese-American mothers in New York City. Journal of community health, 40(3), 476-483.

Leininger, M. (2002). Culture care theory: A major contribution to advance transcultural nursing knowledge and practices. Journal of transcultural nursing, 13(3), 189-192.

Özdemir, C. (2009). Havza ilçesinin genel folklorik yapısı. Journal of International Social Research, 2(7).

Özdemir, S. (2007). Konya ilinde postpartum depresyon sıklığı ve ilişkili sosyodemografik etmenler (Doctoral dissertation, Selçuk Üniversitesi Tıp Fakültesi). 
Özmen, D., Çetinkaya, A., Ç. \& Cambaz, S. Manisa'da 15-49 yaş kadınların gebelik, doğum ve loğusalık ile ilgili geleneksel inanç ve uygulamaları. Ege Üniversitesi Hemşirelik Fakültesi Dergisi, 24(2), 91-102.

Rohde, A., \& Marneros, A. (1993). Postpartum psychoses: onset and long-term course. Psychopathology, 26(3-4), 203-209.

Serhan, N. (2010). Anne ve babalarda postpartum depresyon sıklı̆̆ı ve ilişkili faktörlerin belirlenmesi (Doctoral dissertation, Selçuk Üniversitesi Sağlık Bilimleri Enstitüsü).

Sharma, V., \& Mazmanian, D. (2003). Sleep loss and postpartum psychosis. Bipolar disorders, 5(2), 98-105.

Sit, D., Rothschild, A. J., \& Wisner, K. L. (2006). A review of postpartum psychosis. Journal of women's health, 15(4), 352-368.

Spinelli, M. G. (2009). Postpartum psychosis: detection of risk and management. American Journal of Psychiatry, 166(4), 405-408.

Şahin, Ö. (2018). 6 hafta - 1 yaş bebeği olan annelerde postpartum depresyon sıklı̆̆ ve sosyodemografik risk faktörlerinin değerlendirilmesi. Yayınlanmamış uzmanlık tezi. Katip Çelebi Üniversitesi Aile Hekimliği.

Yalçın, H., \& Koçak, N. (2013). Gebelikle ilgili geleneksel inanç ve uygulamalar ve Karaman örneği. Kent Akademisi, 6(13), 18-34.

Yıldırım, A., Hacıhasanoğlu, R., \& Karakurt, P. (2011). Postpartum depresyon ile sosyal destek arasındaki ilişki ve etkileyen faktörler. Uluslararası İnsan Bilimleri Dergisi, 8(1), 31 46.

Yüksel D. (2007). Gaziantep çevresinde doğumla ilgili inanış ve uygulamalar. Yayınlanmamış Yüksek Lisans Tezi, Gaziantep, Gaziantep Üniversitesi. 